\title{
AVALIAC̃̃̃O DO DESEMPENHO DE UM SISTEMA DE SECAGEM PROJETADO PARA OS PEQUENOS PRODUTORES RURAIS
}

\author{
Performance of a drying system for small farmers
}

\author{
Samir Paulo Jasper ${ }^{1}$, Marco Antônio Martin Biaggioni², Jader Picanço Ribeiro ${ }^{3}$
}

\begin{abstract}
RESUMO
O presente trabalho foi realizado na Fazenda Experimental Lageado, da Universidade Estadual Paulista em Botucatu, SP, e objetivou-se analisar o desempenho de um silo secador alambrado com ar à temperatura ambiente, de projeto simples, com possibilidades de atender às necessidades de pequenos cafeicultores. Para a avaliação do desempenho da secagem, foram realizadas medições do teor de água do café, temperaturas da massa de grãos, do ar de exaustão, do ar de secagem e do ar ambiente, umidade relativa ambiente, velocidade do ar de secagem e o tempo total de secagem. Para avaliar a qualidade do produto seco, foi feito o teste de bebida. Paralelamente, realizou-se a secagem em terreiro para se formar a testemunha. Os resultados observados permitiram concluir que o silo secador alambrado apresentou uma boa eficiência energética, proporcionando um produto seco com o mesmo padrão de qualidade do café seco em terreiro.
\end{abstract}

Termos para indexação: Secagem com ar à temperatura ambiente, café, silo secador alambrado.

\section{ABSTRACT}

This present work was carried out in FCA-Botucatu/UNESP - São Paulo State University, with the aim of evaluating coffee drying performance with near-ambient temperature air-drying system, designed for small farms. The variables measured include: moisture content, grain and air temperatures, relative humidity, drying airflow, drying time and grain quality (beverage). The performance of adopted drying system was compared to open space drying system. The results obtained allowed to conclude that the drying system tested showed very good energy efficiency, without affecting the quality of the beverage.

Index terms: Near-ambient temperature air drying, coffee, drying silo.

(Recebido em 12 de dezembro de 2006 e aprovado em 3 de maio de 2007)

\section{INTRODUÇÃO}

A secagem de café é, comparativamente, mais difícil de ser executada que a de outros produtos. Além da elevada concentração de açúcar presente na mucilagem, o teor de água, aproximadamente $60 \%$ b.u., faz com que a taxa de deterioração seja alta, logo após a colheita. Qualquer que seja o método de secagem utilizado, para condicionar o produto ao armazenamento seguro, busca-se: evitar fermentações indesejáveis antes e durante a secagem; evitar temperatura excessivamente elevada na massa de frutos de café; e procurar, após a secagem completa, quando os frutos tiverem teor de água entre 11 e $12 \%$ b.u., obter lotes de café que apresentem coloração, tamanho e massa específica uniforme (LACERDA FILHO \& SILVA, 2006).

Segundo os mesmos autores, analisando a seqüência de atividades envolvidas na produção do café, como colheita - secagem - armazenamento - pré- processamento - transporte, a secagem é considerada uma operação crítica, geralmente, atribui-se, indevidamente, a ela a causa da deterioração do produto.

Os produtores brasileiros de café vêm enfrentando inúmeros problemas, principalmente no que diz respeito à qualidade final. Para o café são exigidas características organolépticas indispensáveis, que estão diretamente relacionadas com a eficiência do método de secagem adotado, entre outros fatores. Assim, a secagem é uma das operações pós-colheita mais importante e quando mal conduzida resulta em grandes prejuízos para os cafeicultores (SILVA, 1995).

No Brasil, segundo os aspectos tecnológicos envolvidos, utilizam-se basicamente dois métodos para secagem de café: secagem em terreiros - espalha-se o produto sobre pisos de cimento, de tijolo, de chão batido ou de asfalto, com o objetivo de expor o produto diretamente à radiação solar; e a secagem artificial, em secadores mecânicos. Nessa secagem, a fonte de calor

\footnotetext{
'Engenheiro Agrônomo, Doutorando - Departamento de Engenharia Rural/DEnR - Faculdade de Ciências Agronômicas/FCA - Universidade Estadual Paulista/UNESP - Fazenda Lageado, Rua José Barbosa de Barros, 1780 - Cx. P. 237 - 18610-307 - Botucatu, SP - jasper@fca.unesp.br

${ }^{2}$ Doutor, Professor Assistente- Departamento de Engenharia Rural/DEnR - Faculdade de Ciências Agronômicas/FCA - Universidade Estadual Paulista/ UNESP - Fazenda Lageado, Rua José Barbosa de Barros, 1780 - Cx. P. 237 - 18610-307 - Botucatu, SP - biaggioni@fca.unesp.br

${ }_{3}^{3}$ Mestrando - Departamento de Engenharia Rural/DEnR - Faculdade de Ciências Agronômicas/FCA - Universidade Estadual Paulista/UNESP - Fazenda Lageado, Rua José Barbosa de Barros, 1780 - Cx. P. 237 - 18610-307 - Botucatu, SP - picanco@fca.unesp.br
} 
pode ser variável. O que caracteriza um método como artificial é o fato de que o processo é executado com o auxílio de alternativas mecânicas, elétricas ou eletrônicas e o ar, que atravessa a massa de sementes, é forçado (CAVARIANI, 1996). Apresenta a vantagem de permitir o controle da temperatura, do fluxo do ar de secagem e do tempo de exposição das sementes ao ar aquecido, fatores fundamentais para garantir a eficiência do processo.

Baseada na capacidade do ar fornecer calor e na necessidade de aumentar a temperatura do ar, segundo Villela (1991), a secagem artificial pode ser dividida em duas categorias: secagem em baixa temperatura, na qual se utiliza o ar natural ou aquecido de 1 a $8^{\circ} \mathrm{C}$ acima da temperatura ambiente e secagem em alta temperatura, que consiste em aquecer o ar a temperaturas superiores a $8^{\circ} \mathrm{C}$.

Atualmente, o consumo de energia, o rendimento e a temperatura de um secador são parâmetros aos quais têm sido dado grande ênfase na escolha de um sistema de secagem, pois podem interferir na taxa de deterioração e mudança de cor, resultando num produto de baixa qualidade (CORDEIRO, 1982).

Por outro lado, com a extinção da Empresa Brasileira de Assistência Técnica e Extensão (EMBRATER), no início dos anos noventa, ocorreu a escassez de informações técnicas e da disponibilidade de tecnologias, principalmente para os pequenos produtores.

Tal fato deve-se, principalmente, à falta de incentivo das indústrias em desenvolver produtos e equipamentos específicos para pequenos produtores ficando, normalmente, essa tarefa para os órgãos públicos e órgãos de pesquisa (SILVA, 1995).

Com a proposta atual do governo, voltada a promover o desenvolvimento da agricultura familiar e dos pequenos produtores rurais, algumas indústrias preocuparam-se em oferecer equipamentos adequados à capacidade de produção desses, mantendo as mesmas preocupações de qualidade relativa aos grandes produtores.

Visando avaliar o potencial de um novo equipamento de secagem de grãos que busca reunir os princípios de secagem com qualidade (baixa temperatura) e o acesso para o pequeno produtor (projeto simples), o presente trabalho propõe-se a avaliar o desempenho do Silo Alambrado, durante a complementação da secagem de frutos de café.

\section{MATERIALE MÉTODOS}

O trabalho foi conduzido na Fazenda Experimental Lageado, no Departamento de Engenharia Rural (Laboratório de Processamento de Produtos Agrícolas) e na Unidade de Processamento de Grãos, da Faculdade de Ciências Agronômicas do Campus da UNESP-Botucatu/ SP. Processaram-se frutos de café procedentes da Cooperativa de Cafeicultores da Zona de São Manuel (CAFENOEL), localizada em São Manuel/SP.

Os frutos de café (Coffea arábica L.), da variedade Catuaí, foram colhidos com teor de água de, aproximadamente, $60 \pm 5 \%$ b.u., sendo encaminhados para pré-secagem em terreiro, na propriedade, até atingir teor de água próximo a $20 \%$ b.u. (BAKKER-ARKEMA et al., 1978). Durante a carga do silo, amostras foram coletadas para análises de teor de água e massa específica. Para fins de comparação, conduziu-se uma secagem em terreiro (testemunha), até teor de água final abaixo de $12 \pm 1 \%$ b.u.

\section{Sistemas de secagem}

Silo secador alambrado. O silo, do Grupo Fockink, é constituído pelo corpo, sistema de secagem, sistema de descarga e o sistema controlador.

O corpo do silo secador é formado por um conjunto de tela metálica ( $3 \times 3$ polegadas), que depois de parafusada constitui a parte estrutural do corpo. $O$ sistema de fixação é por parafusos e montantes estruturais em perfis metálicos, fixados à estrutura de tela metálica para permitir a adequada resistência mecânica do conjunto. Completando a estrutura do corpo, é utilizada uma tela de PVC, adequadamente dimensionada e dotada de perfuração para permitir a passagem do ar do sistema de secagem. A capacidade do silo secador é de aproximadamente $29 \mathrm{~m}^{3}$.

O sistema de secagem é composto por um cone metálico perfurado, adequadamente dimensionado para promover um fluxo de ar radial, ou seja, o ar entra pelo cone metálico, atravessa a camada de grãos, promovendo a secagem e sai através da tela do corpo, os dutos de condução de ar entre ventilador e cone metálico perfurado, executados em chapas de aço e o ventilador em aço galvanizado, acionado por motor elétrico (1,5 CV), dimensionado de acordo com cada tamanho de silo.

O sistema de descarga é constituído por um duto metálico, equipado com registro, acionado por hastes desde a parte externa do silo. Nesse duto é introduzida uma rosca transportadora para fazer a remoção dos grãos, ou onde poderá ser fixado o ventilador, utilizando-o como duto condutor entre o ventilador e o cone metálico perfurado.

Na secagem em terreiro (testemunha), adotou-se a metodologia de Silva (1995), sendo que, diariamente, os frutos de café eram espalhados com auxílio de um rodo, sobre uma área de, aproximadamente, dez metros quadrados, fazendo uma camada de cerca de três a cinco 
centímetros e, ao entardecer, eram amontoados e cobertos com sacos de aniagem e lona plástica. Ao amanhecer, novamente, espalharam-se os grãos na mesma área, repetindo o processo, até as amostras atingirem o teor final de água.

\section{Análises dos sistemas de secagem}

As variáveis utilizadas para as análises dos sistemas de secagem foram propostas por Bakker-Arkema et al. (1978), apresentadas a seguir: a) parâmetros dos grãos - tipo de grãos, teor de água inicial e final (\% b.u.), temperaturas de entrada e de saída $\left({ }^{\circ} \mathrm{C}\right)$, massa específica antes e após a secagem $\left(\mathrm{kg} \mathrm{m}^{3}\right)$, análise da qualidade final; b) parâmetros do ar - temperatura do ar utilizado para a secagem e do ambiente $\left({ }^{\circ} \mathrm{C}\right)$ e umidade relativa do ambiente $(\%)$.

\section{Monitoramento dos parâmetros}

Temperaturas. As medidas de temperatura do ar ambiente foram feitas em um termohigrógrafo, instalados em um abrigo meteorológico, conforme os padrões técnicos recomendados pelo Ministério da Agricultura e localizados na área de experimentação. No silo secador alambrado, as leituras de temperaturas, em diversos pontos da massa de frutos de café (Figura 1 - A), foi monitorado com o uso de termopares de cobre-constantan (Tipo T), com isolação em PVC, bitola 2 x 24 AWG e um registrador de temperaturas, cujas leituras foram feitas em graus Celsius.
Todas essas informações serviram de base para os cálculos de eficiência de secagem, eficiência energética e acompanhamento da qualidade dos frutos de café durante a secagem.

Vazão de ar. A vazão de ar no secador de fluxos concorrentes foi obtida através da curva característica do ventilador. Na câmara plenum foram construídos pontos para as medidas da pressão estática, que foram feitas com a utilização de um manômetro diferencial inclinado, cujas leituras se fizeram em equivalência de coluna de água.

Análises laboratoriais. As amostras eram coletadas, semanalmente, na fase inicial e intermediária do processo e, diariamente, quando as mesmas apresentaram teor de água abaixo de $12 \%$ b.u.

Coletaram-se as amostras, manualmente, com calador multicompartimentado, em 15 posições do silo secador alambrado, ao longo de um raio (Raio 1, Figura 1 B). A fim de avaliar a uniformidade do processo de secagem, coletaram-se, por duas ocasiões, amostras em 45 posições, distribuídas ao longo de três raios (Figura 1 - B). As amostras da secagem em terreiro foram coletadas manualmente.

Teor de água dos frutos de café. O teor de água dos grãos foi medido em estufa, com circulação forçada, atendendo às normas estabelecidas pela "American Association of Cereal Chimists", isto é, $105 \pm 2{ }^{\circ} \mathrm{C}$, durante $72 \mathrm{~h}$. As amostragens seguiram os critérios do Ministério da Agricultura (BRASIL, 1992).

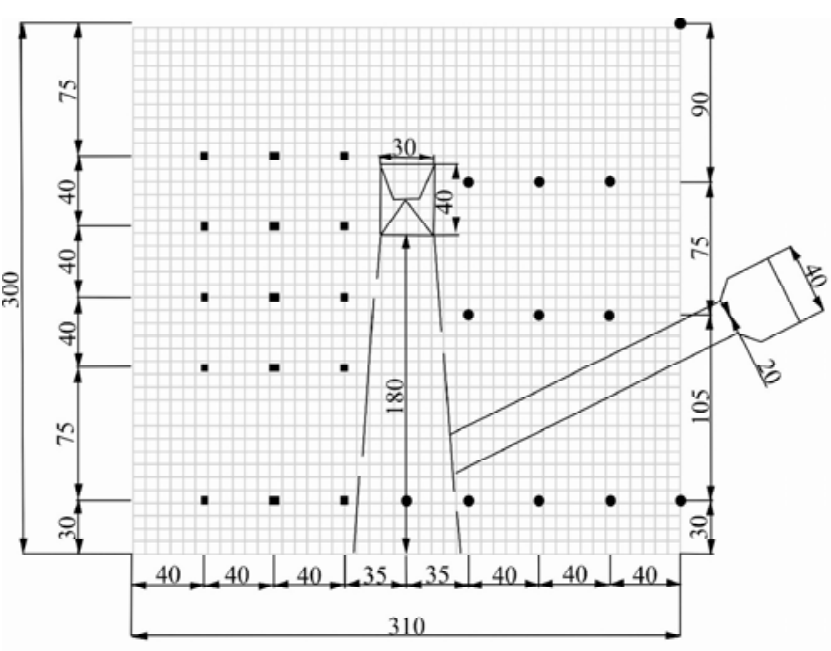

(A)

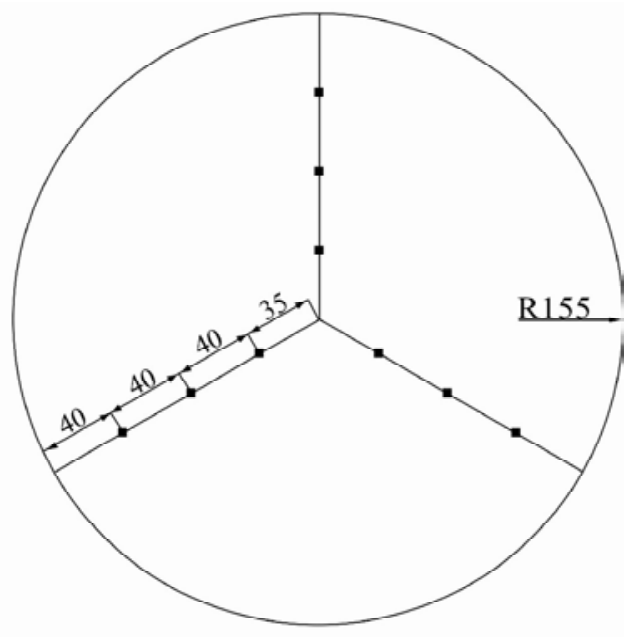

(B)

Figura 1 -Esquematização: (A) Sensores de temperatura na massa de frutos de café, durante o processo de secagem; (B) Dos 15 pontos de coleta utilizados para determinação do teor de água da massa de café grãos, em três raios distintos. 
Peso hectolitro - Amostras para determinação da massa específica foram coletadas durante as operações de carga e descarga do silo secador alambrado. Para tanto, utilizou-se de uma balança de peso hectolitro, com capacidade de $1 / 4$ de litro, com 4 repetições.

Avaliação da qualidade do produto. Após a secagem o produto foi encaminhado para Cooperativa de Cafeicultores da Zona de São Manuel (CAFENOEL), para classificação da bebida, através do teste da xícara, seguindo as normas do IBC (1981).

\section{RESULTADOS E DISCUSSÃO}

Secagem no terreiro. A redução do teor de água do café secado em terreiro (testemunha) observa-se na Figura 2.

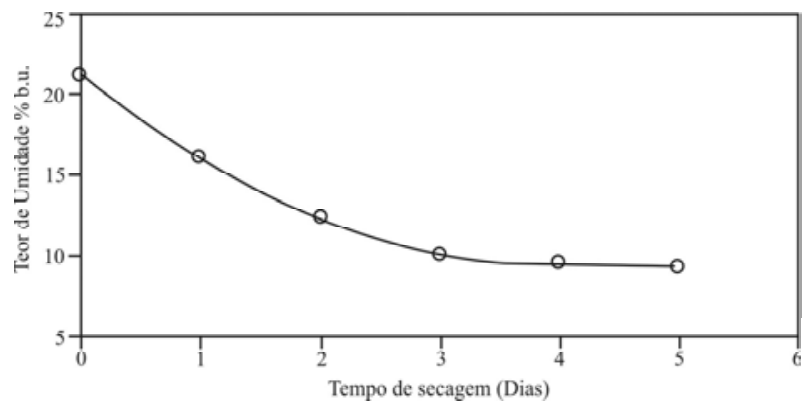

Figura 2-Curva de Secagem do Café em Terreiro.

Como toda secagem em baixa temperatura, a secagem em terreiro é dependente das condições climáticas. A temperatura, a umidade relativa e o vento são fatores fundamentais na taxa de secagem do produto, uma vez que existe uma capacidade máxima do ar em evaporar a água contida no produto. Entretanto, analisando-se a Figura 3 , verifica-se o bom desempenho desse sistema, necessitando, apenas de 5 dias, para reduzir o teor de água de $21,2 \%$ para $9,4 \%$, sendo removidos $7 \mathrm{~kg}$ de água, aproximadamente. Provavelmente, a espessura da camada de grãos (3 a $5 \mathrm{~cm}$ ), como o revolvimento constante dos frutos de café, corroboraram para secagem do produto.

Secagem no silo - Curva de secagem. Na Figura 3, representam-se as curvas de secagem do café secado no Silo Alambrado Ventilável, com ar em temperatura próxima à ambiente, nos cincos níveis de profundidades monitoradas. Nota-se que a curva de redução de água dos frutos de café apresentou variações características para a secagem em silo, isto é, uma queda rápida no teor de água do produto localizado próximo ao local de entrada de ar, ou seja, no quinto dia, a camada de $30 \mathrm{~cm}$ de café, já estava com teor de água inferior a $14 \%$ b.u. A partir do quinto dia, a frente de secagem do café encontrava-se entre as camadas de 105 a $145 \mathrm{~cm}$; acima dessa camada, a massa de frutos de café permaneceu ainda úmida, chegando a se obter, ao final do processo, produto com teor de água próximo a $10 \%$ b.u.

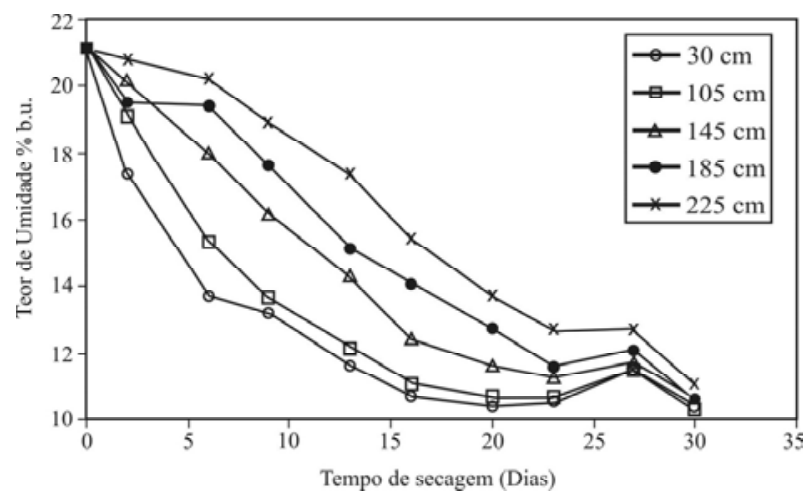

Figura 3 - Curvas de secagem em cincos níveis de profundidades monitoradas.

Um dos problemas típicos do processo de secagem, com ar em temperatura próximo, à ambiente, está no fato do teor de água final a ser atingido pela massa de grãos sempre é determinado pelo potencial de secagem da região. Analisando-se os teores de água, verifica-se que a interação da temperatura e umidade relativa do ar (potencial de secagem) favoreceu o processo obtendo-se, após 15 dias de secagem, café com teor de água abaixo de $13 \%$ b.u., nas três primeiras camadas, o que corresponde a $50 \%$ da massa de café.

Verifica-se, entretanto, ainda pela análise da Figura 3 , que a secagem no silo, demandou um período de 30 dias para reduzir o teor de água de $21,16 \%$ para $10,59 \%$ b.u. Pode-se considerar esse tempo seguro, pois a vazão de ar alcançou as camadas superiores de secagem sem ocorrer a deterioração do produto úmido. Em relação à secagem em terreiro, as principais vantagem do silo secador alambrado consistem na elevada capacidade de secagem por unidade de área, na baixa necessidade de mão-de-obra e ser menos vulnerável à intempéries.

Além da análise técnica da secagem com ar em temperatura próxima à ambiente, é importante verificar sua eficiência energética, isto é, a relação entre a quantidade de energia fornecida ao sistema e a quantidade de água retirada. Reduzir o gasto de energia constitui-se num benefício para esse sistema de secagem, o que somente poderá ser obtido se não houver risco de deterioração. Para as condições do presente trabalho, no qual foram 
necessárias 680 horas de secagem para retirar cerca de 950 kg de água, o consumo específico de energia atingiu um valor de $4.126 \mathrm{~kJ} / \mathrm{kg}$ de água evaporada, o que pode ser considerado razoável, em relação a outros sistemas de secagem com ar natural e a baixas temperaturas, ficando próximo aos $3.800 \mathrm{~kJ} / \mathrm{kg}$, obtidos por Johson \& Otten (1980).

Uniformidade da Secagem. Na Figura 4, observamse as curvas de umidade das amostras de café coletados em três raios, para primeira e quarta semana de secagem, respectivamente. Nota-se que, em nenhum dos momentos a variação do teor de água foi superior a $2 \%$, nas diferentes profundidades monitoradas, concluindo-se que a secagem foi uniforme em todas as direções do silo.

Monitoramento das temperaturas. Durante todo o processo de secagem do produto, fez-se o acompanhamento da temperatura da massa de frutos de café, em diferentes pontos do silo secador alambrado, da temperatura do ar de secagem (plenum) e da temperatura do ambiente, objetivando monitorar a qualidade do processo de secagem.

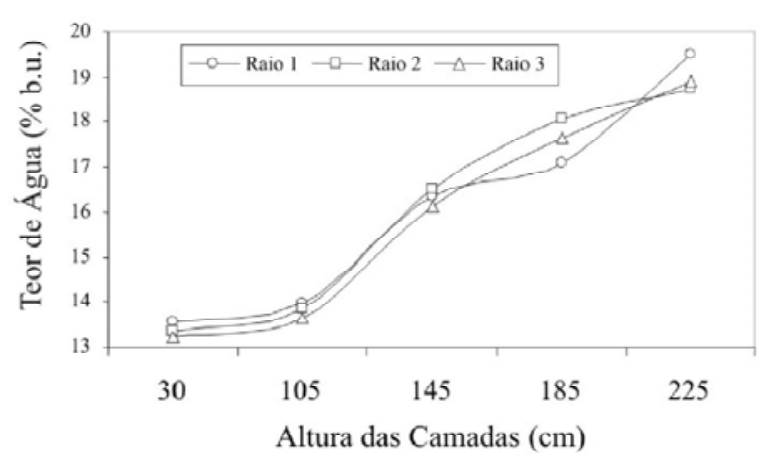

(A)
As leituras foram realizadas no período da manhã e no período da tarde (Figuras 5 e 6, respectivamente).

Analisando-se as curvas de temperatura na Figura 6 , verifica-se, antes de iniciar o processo de secagem, a elevada temperatura da massa de grãos em função, principalmente, do calor adquirido pelo produto durante $o$ transporte. Interpretando as variações de temperatura nas diferentes camadas (Figura 6), observa-se que, em todo o processo de secagem, a camada superior $(180 \mathrm{~cm})$ registrou as menores temperaturas, e isso pode ser atribuído ao resfriamento evaporativo ocasionado nessa camada, ou seja, o processo de secagem foi mais lento nessa região. Apresentam-se na Figura 7, as variações de temperaturas registradas no período da tarde. Como já era esperado, houve um aumento das temperaturas nas diferentes camadas de grãos, ocasionado pelo aumento da temperatura do ambiente.

Os valores médios de temperatura e umidade relativa do ar ambiente, as condições iniciais do produto e os

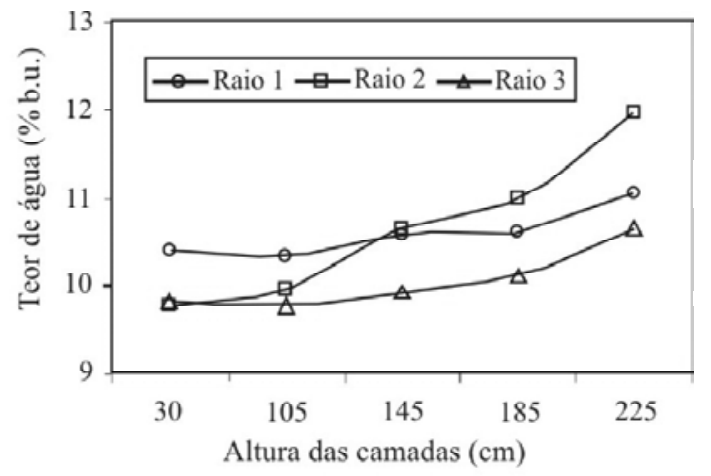

(B)

Figura 4-Curva de secagem em três raios distintos: (A) primeira semana de secagem e (B) quarta de semana de secagem.

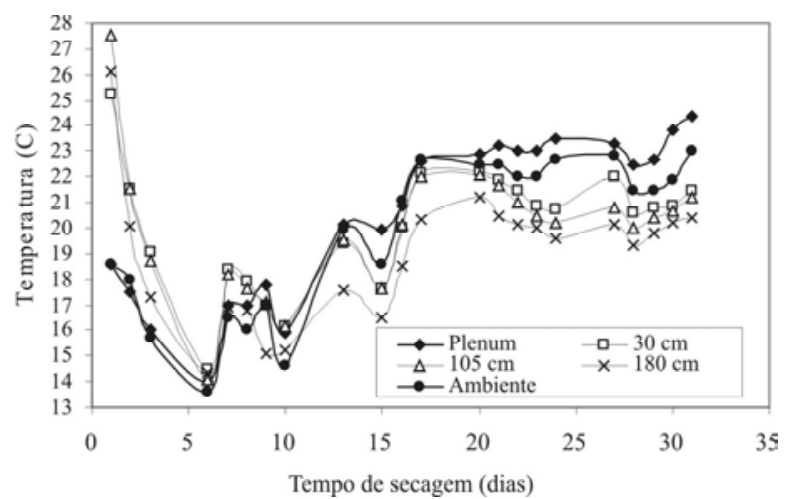

Figura 5 - Variação média entre as temperaturas do ar ambiente, de secagem e da massa de grãos durante a secagem, no período da manhã (08h00min).

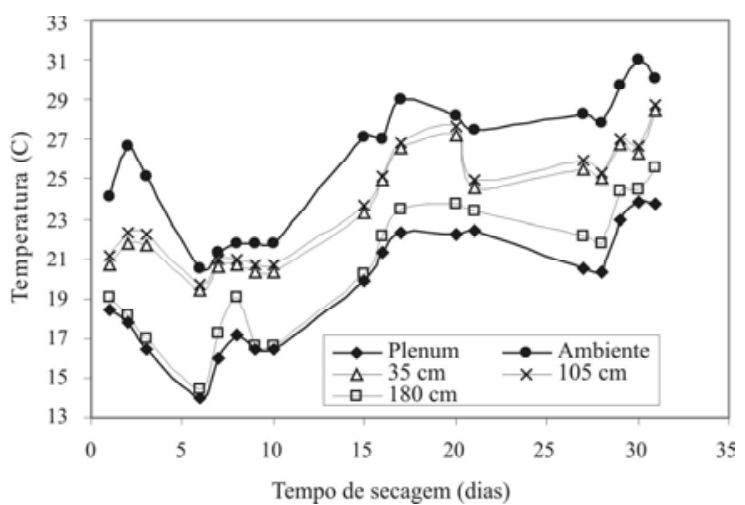

Figura 6 - Variação média entre as temperaturas do ar ambiente, de secagem e da massa de grãos durante a secagem, no período da tarde (17h00min). 
Tabela 1 - Condições iniciais médias do ar e dos grãos no experimento.

\begin{tabular}{llcc}
\hline & Condições do teste & Silo secador alambrado & Terreiro \\
\hline \multirow{2}{*}{ Ar ambiente } & Temperatura $\left({ }^{\circ} . \mathrm{C}\right)$ & 23,97 & 17,84 \\
& Umidade relativa $(\%)$ & 45,84 & 65,62 \\
\multirow{3}{*}{ Ar de secagem } & Temperatura $\left({ }^{\circ} . \mathrm{C}\right)$ & 21,29 & - \\
\multirow{3}{*}{ Produto } & Fluxo de ar $\left(\mathrm{m}^{3} / \mathrm{min} \mathrm{m}^{3}\right)$ & 6,63 & - \\
& Teor de água $(\%$ b.u. & 21,16 & 21,16 \\
& Massa especifica $\left(\mathrm{kg} / \mathrm{m}^{3}\right)$ & 365,14 & 365,14 \\
\hline
\end{tabular}

Tabela 2 -Condições médias finais para o experimento.

\begin{tabular}{lcc}
\hline \multicolumn{1}{c}{ Condições do teste } & Silo secador alambrado & Terreiro \\
\hline Tempo de secagem $(\mathrm{h})$ & 680 & 120 \\
Teor de água $(\%$ b.u. $)$ & 10,59 & 9,39 \\
Massa especifica $\left(\mathrm{kg} / \mathrm{m}^{3}\right)$ & 363,63 & 359,71 \\
Teste de bebida & Dura & Dura \\
\hline
\end{tabular}

parâmetros de secagem obtidos no experimento constatamse nas Tabelas 1 e 2 .

De acordo com Silva et al. (1992), a vazão mínima recomendada para secagem de café em coco, com ar de secagem próximo à temperatura ambiente, é de $2,5 \mathrm{~m}^{3} \mathrm{~min}^{-1} \mathrm{~m}^{-3}$, nota-se que a vazão do silo secador alambrado foi bem superior a esse parâmetro.

Em relação aos resultados apresentados sobre a massa específica (Tabela 2), verifica-se que houve uma pequena redução após a secagem, passando de $365,14 \mathrm{~kg} / \mathrm{m}^{3}$ para, em média, 363,23 kg/m³ confirmando os dados de Afonso (1994) que encontrou pequena alteração na massa específica aparente do café em coco, após o ponto de meia-seca (31\% b.u.). Referente a qualidade da bebida, ambos os sistemas de secagem tiveram a bebida classificada como bebida dura.

\section{CONCLUSÕES}

A análise de desempenho do Silo Secador Alambrado revelou constituir-se numa opção viável aos produtores de café da região, realizando uma secagem complementar, a partir do teor de água $21 \%$ b.u. , sem comprometer a qualidade final do produto.

\section{REFERÊNCIAS BIBLIOGRÁFICAS}

AFONSO, A. D. L. Gradiente de pressão estática em camadas de frutos de café (Coffea arábica L.) com diferentes teores de umidade. 1994. 68 f. Dissertação (Mestrado em Engenharia Agrícola) - Universidade Federal de Viçosa, Viçosa, 1994.
BAKKER-ARKEMA, F. W.; LEREW, L. E.; BROOK, R. C.; BROOKER, D. B. Energy and capacity performance evaluation of grain dryers. Michigan: ASAE, 1978. 13 p.

BRASIL. Ministério da agricultura. Regras para análise de sementes. Brasília, DF: DNPOV-DISEN, 1992.365 p.

CAVARIANI, C. Secagem estacionária de sementes de milho com distribuição radial do fluxo de ar. 1996. $85 \mathrm{f}$. Tese (Doutorado em Produção Vegetal) - Escola Superior de Agricultura de Luiz de Queiroz, Piracicaba, 1996.

CORDEIRO, J. A. B. Influência da temperatura e tempo de repouso na secagem de café (Coffea arábica $L$.) em camada fixa. 1982. 60 f. Dissertação (Mestrado em Engenharia Agrícola) - Universidade Federal de Viçosa, Viçosa, 1982.

INSTITUTO BRASILEIRO DO CAFÉ. Cultura do café no Brasil: manual de recomendações. 4. ed. Rio de Janeiro, 1981. $503 \mathrm{p}$.

JOHNSON, P. D. A.; OTTEN, L. Solar-assisted, lowtemperature corn drying in Southern Ontario. Ottawa: [s.n.], 1980.

LACERDA FILHO, A. F.; SILVA, J. de S. E. Secagem de café em combinação. Engenharia Agrícola e Ambiental, Campina Grande, v. 10, n. 3, p. 671-678, 2006.

SILVA, J. de S. E. Pré-processamento de produtos agrícolas. Juiz de Fora: UFJF, 1995. 509 p. 
SILVA, J. de S. E.; AFONSO, A. D. L.; GUIMARÃES, A. C.; BIAGGIONI, M. A. M. Análise dos sistemas de secagem. Engenharia na Agricultura, [S.1.], v. 2, n. 5, p. 1-31, 1992.
VILLELA, F. A. Efeitos da secagem intermitente sobre a qualidade de sementes de milho. 1991. 104 f. Tese (Doutorado em Produção Vegetal) - Escola Superior de Agricultura de Luiz de Queiroz, Piracicaba, 1991. 